\title{
Editorial
}

\section{0: ¿hacia la pacificación y la democracia?}

Se ha dicho que el siglo XXI ha comenzado ya en 1990. Son innegables los cambios que a nivel mundial, y también latinoamericano, se vienen dando entre la pasada y la presente década. Un claro rechazo a las dictaduras monopartidistas y a los gobiernos presidenciales militaristas; un alto a la carrera armamentística acompañado de un proceso de diálogos bilaterales; una negativa generalizada a las guerras frias y calientes y un voto afirmativo por la paz; una transferencia de la lucha armada a favor de los compromisos políticos. Los cambios sociales se buscarian más por la via electoral que por medio de las revoluciones armadas. Un nuevo valor, la democracia, pasa a ser el objetivo número-uno al iniciar el siglo $X X I$. Todos estos cambios se están interpretando como un brusco giro que el mundo actual está dando hacia la derecha. Por lo menos eso se dice en nuestro pequeno occidente centroamericano.

No hay duda de que este serial de cambios políticos contienen elementos altamente positivos y democráticos. Las dictaduras monopartidistas del Este europeo, asi como las dictaduras militares del oeste latinoamericano eran una negación de las respectivas democracias. Frente al dictado se opta por la elección, y con más o menos limpieza aquellos y estos paises se entrenan en el campo de los procesos electorales. No es que se haya logrado la plena limpieza y la mayor apertura democrática. Seguimos escuchando fuertes reclamos en varios paises salidos del socialismo-real, porque los detentores del antiguo poder ponen trabas a los nuevos movimientos emergentes. Pero nos resistimos a aceptar que en muchos de nuestros palses no 
todos los gnupos populares o partidos de oposición hallan via libre en los procesos electorales por razones de seguridad personal o de cortapisas jurídicas. Más grave aún, manipulamos el resultado de las elecciones de acuerdo a nuestra posición doctrinaria. Un caso típico es el sorprendente resultado de las elecciones en Nicaragua. El resultado no seria $\tan$ sorprendente si entendermos que el rechazo no fue a los objetivos sociales del sandinismo, sino una clara negativa al proceso de guerra y penuria económica en que, desde fuera, se vió enrolado el movimiento sandinista. Siendo razonables diversas interpretaciones, algo quedó claro: que esas elecciones se hicieron en forma democrática y que la democracia es el gran reto para el nuevo gobierno salido del voto popular.

Con mayor o menor transparencia, los procesos electorales centroamericanos, de acuerdo al trabajo de Gabriel Gaspar Tapia ("La derrota sandinista y el nuevo marco regional") han generado los siguientes efectos. A) La Consolidación de sistemas políticos basados en elecciones competitivas para designar a los gobernantes. B) La emergencia de una derecha renovada en la región centroamericana, portadora de un proyecto de reorganización económica y que reivindica la democracia política. C) La constitución de un bloque de paises aliados de EE.UU. con mayor legitimidad. D) EI predominio de las opciones pacifistas y democratizadoras por sobre ópticas de transformación social.

El hecho de que en el Este europeo como en nuestro oeste centroamericano hayamos iniciado un proceso de elecciones más libres y pluralistas no significa, ipso-facto, que nos hayamos transformado en sociedades más democráticas. Nuestra democracia es todavia una democracia de baja intensidad, como to deja entender el siguiente párrafo de G. Gaspar Tapia: "Si entendemos a la democracia, no como un método, sino como una condición social entonces tenemos que impugnar el grado de democratización que pueda darse en sociedades donde no se permite el pluralismo, se persigue a los disidentes, se violan los derechos humanos, y el poder civil no logra subordinar al poder militar; los cuales, entre otros aspectos, son caracteristicas de vida cotidiana de muchos paises centroamericanos, a pesar de que en ellos se lleven a cabo procesos electorales con rigurosa regularidad desde hace algunos anos". En tales condiciones, en nombre de la democracia seguiriamos siendo antidemocráticos.

Siendo la democracia la tarjeta de entrada al siglo XXI es algo Kógico y cronológico que en el trabajo titulado: "¿ hacia dónde va el Este y hacia dónde va el Oeste?" aparezca el mismo tema, a la luz del foro 
de Moscú (junio-1989), la macroencuesta en el Este-Oeste europeo (enero-1990) y el encuentro de Paris (febrero-1990) dedicados todos ellos a la post-perestroika. Las ponencias y conclusiones de estos importantes eventos y los resultados de la macroencuesta pueden perfeccionar y enriquecer nuestra traducción del concepto democracia, tanto por to que hace al serial de intolerancias criticadas como por los aspectos positivos que se esperan de una democracia a nivel nacional e internacional. Estas lecturas son importantes en nuestros medios, porque al cefirse la democracia a una negación de la dictadura estatal y a una afirmación de los simples procesos electorales podemos derivar hacia otro tipo de dictaduras disimuladas bajo capa de libertad. La interpretación de los hechos del Este europeo y de nuestro cercano oeste ha generado la emergencia de una "derecha renovada" en la región centroamericana, portadora de un proyecto de reorganización económica y que reivindica la democracia política. Sucede que terminologias opuestas pueden conducir a errores sociales semejantes; del mismo modo que calificativos parecidos encierran motivaciones y objetivos opuestos. A este respecto, el Dr. Luis de Sebastián trató de mostrar (Realidad Económica y Social, sept. oct. 1989) que el neoliberalismo actual en poco se asemeja al liberalismo económico clásico; más bien se trata de un movimiento opuesto a los ideales, motivaciones y objetivos económicos y sociales que tuvo el primero. Resulta, de hecho, que el término neo-liberalismo equivale a no-liberalismo.

A este nuevo liberalismo responde el trabajo dedicado al análisis de "la nueva derecha en El Salvador", que por su amplitud se ha distribuido entre el pasado y presente número de la revista. Tanto como los representantes concretos de esta nueva corriente interesa desmembrar los componentes de este "modelo de hegemonia" en su nivel económico y político social. Sus principios económicos se basan en el realismo, pragmatismo, eficiencia, productividad, rentabilidad. Conjugados a ellos los principios políticos de democracia plebiscitaria, anticomunismo pragmático, despolitización de las masas y desigualdades sociales, el nuevo liberalismo se transforma en una nueva hegemonia. Sobra decir que, aunque el modelo económico encierra sus aspectos nacionalistas, es más bien intemacionalista y bien aceptado por los EE.UU., puesto que allá fué procesado. El andamiaje técnico macroeconómico y sus objetivos primordialmente financieros del equilibrio externo, relegan a un siempre lejano futuro el desequilibrio interno y estructural de las desigualdades sociales. Con ello se pone en duda los verdaderos deseos de la pacificación social que pretendería el modelo. En otras palabras, el modelo neoliberal no ha entendido que 
nuestra guerra no es congénitamente comunista sino antipobreza generalizada. Dudamos que este sea el modelo del desarrollo, de la pacificación y de la democracia.

La nueva derecha y el nuevo liberalismo fundamentan gloriosamente sus principios en una parcial y defectuosa interpretación de las bruscas convulsiones que, en el pasado y presente ano, se han llevado a cabo en el Este europeo. Se afirma simplemente: el socialismo está muerto y sepultado; el comunismo es el camino más largo para pasar del capitalismo al capitalismo. Sin embargo, si al trabajo se le ha titulado: ¿hacia dónde va el Este, hacia dónde va el Oeste?, no es porque el Este camine hacia el Oeste, sino por que Este y Oeste deben caminar hacia una nueva democracia económica humana. Los europeos de la macroencuesta y de los foros de Moscú y Parls marcan una clara diferencia entre comunismo, socialismo real y socialdemocracia, dando al liberalismo un cariz más político que económico. El rechazo masivo al socialismo real, al históricamente impuesto en los paises del bloqueEste, no significa una negación del espiritu y de los objetivos defendidos desde el pasado siglo por la socialdemocracia y socialismos de Occidente. Incluso la macroencuiesta corrida en ocho de esos palses del Este-Oeste europeo privilegia estadisticamente la opción de la socialdemocracia. Con todo, la encuesta recibirá una ilustrativa interpretación en el Foro de París.

Yendo en orden, los treinta participantes soviéticos del foro de Moscú (junio-1989) unánimemente se pronuncian en contra de la intolerancia política, especialmente contra la intolerancia de la nación hegemónica y del partido único oligárquico, contra la intolerancia de la comupción y del dogmatismo de los detentores del poder. La discusión y la disyuntiva no es entre plan y mercado, sino entre poder político oligárquico y poder político democrático. Al transferir el punto central en cuestión al litigio de mercado versus planificación lo único que la nueva derecha puede y quiere buscar es el fortalecimiento de la hegemonia de la nación lider y de la oligarqula del mercado. Así, en nombre de la Perestroika se pretende hacer anti-perestroika. Por ello interesa escuchar los resultados de la macroencuesta europea tal como se debatió en el encuentro de París: conservadores en lo económico, socialdembcratas en lo demás. Aunque distemos físicamente, nos situamos históricamente muy cercanos de esos paises: ellos y nosotros somos naciones en búsqueda del nuevo sistema, que será algo más que una"tercera-via" salida de una mezcla de los dos hoy existente.

Importantes para nosotros los resultados de la macroencuesta, porque al encasillar las opciones en términos de liberalismo-comunismo- 
capitalismo-socialismo democrático-social-democracia, nos muestra que esos conceptos significan algo muy distinto en los distintos países. Más aún, que tales altemativas patidistas no integran las verdaderas opciones populares, traducidas en nuevos movimientos nacionales, a veces nacionalistas. Incluso se percibe una alergia y desconfianza hacia los partidos políticos que buscan su poder, más que el servicio al pueblo. Tal vez, uno de los rasgos del nuevo siglo será que los partidos políticos compartan el poder con los movimientos democráticos nacionales. Si la democracia es el objetivo, a ella deben plegarse las modalidades de ejercer la política.

Un nuevo elemento une el destino europeo y el centroamericano: en ambas latitudes se habla de mercado común. El nuevo Mercado Común Europeo ha pasado a ser el punto focal de las grandes naciones industrializadas ("La post-perestroika...; ECA, abril-1990). Tal vez, al mismo tiempo que se derriba el muro de Berlín, se levanta el "muro del Sur". El Oeste va hacia el Este, y se olvida del Sur. Esta amenaza puede ser real; pero hay que ver el lado positivo, to que esos países nos ensenan. Si Europa quiere ser el "hogar-común", deberá unir naciones que vienen de modelos y situaciones tan diversas, de historias enfrentadas, de movimientos nacionalistas emergentes, cada cual con sus nostalgias y sus mútuos temores. Si a la nueva-Europa se la contempla y analiza sólo como un gran mercado común, se corre el peligro de desintegrarla por medio de la competencia tecnológica y mercantil, resurgiendo los nacionalismos a la defensiva. La nueva Europa se salvará, y nos podrá salvar, si sus miembros integrantes la ven como un hogar-común, donde las relaciones de competencia se cambian en relaciones de colaboración y mútuo servicio. Son estos los anhelos que afloran en el foro de París.

La aplicación es clara al istmo y continente latinoamericano. Por un lado, el modelo neoliberal, traducido en un programa de ajuste estructural macroeconómico y financiero, viene a reforzar, con las leyes del mercado, un enfoque competitivo y nacionalista de nuestras relaciones internacionales sometidas al dictamen del pais dominante. La dimensión centroamericana y latinoamericana se difumina en las variables anónimas de nuestras balanzas de pagos, mientras que el desarrollo social queda relegado a programas subsidiarios. Por el otro lado, los procesos electorales realizados y por realizar en el presente ano en el istmo centroamericano y el ascenso de gobiernos civiles, deben aprovecharse para crear nuestro hogar-común centroamericano. Aquí es donde surge el conflicto teórico y práctico entre la nueva derecha que trata de imponerse y la nueva democracia más social y centroamericana. 
Europa y Centroamérica están cansadas de las guerras frias y calientes, están en contra de las oligarquias estatales y mercantilistas, están frustradas por los partidos políticos que buscan su propio poder; rechazan las hegemonias y los imperialismos transnacionales y buscan las democracias al interior de cada nación y también en las relaciones internacionales.

San Salvador, febrero de 1990. 